Article

\title{
Two Isomeric C16 Oxo-Fatty Acids from the Diatom Chaetoceros karianus Show Dual Agonist Activity towards Human Peroxisome Proliferator-Activated Receptors (PPARs) $\alpha / \gamma$
}

\author{
Angel Moldes-Anaya ${ }^{1,2}$, Thomas Sæther ${ }^{1,3}$, Silvio Uhlig ${ }^{4}$, Hilde I. Nebb ${ }^{3}$, Terje Larsen ${ }^{1}$, \\ Hans C. Eilertsen ${ }^{5}$ and Steinar M. Paulsen ${ }^{2, *}$ \\ 1 Cardiovascular Research Group, Department of Medical Biology, UiT The Arctic University of Norway, \\ 9019 Tromsø, Norway; angel.moldes-anaya@uit.no (A.M.-A.); thomas.sather@imbv.uio.no (T.S.); \\ terje.larsen@uit.no (T.L.) \\ 2 MabCent-SFI, UiT The Arctic University of Norway, 9019 Tromsø, Norway \\ 3 Department of Nutrition, Institute of Basic Medical Sciences, University of Oslo, 0313 Oslo, Norway; \\ h.i.nebb@medisin.uio.no \\ 4 Section for Chemistry, Norwegian Veterinary Institute, 0106 Oslo, Norway; silvio.uhlig@vetinst.no \\ 5 Norwegian College of Fishery Science, UiT The Arctic University of Norway, 9019 Tromsø, Norway; \\ hans.c.eilertsen@uit.no \\ * Correspondence: steinar.paulsen@uit.no; Tel.: +47-776-44504
}

Academic Editor: Paul Long

Received: 9 February 2017; Accepted: 18 May 2017; Published: 25 May 2017

\begin{abstract}
The peroxisome proliferator-activated receptors (PPARs) function as ligand-activated transcription factors that convert signals in the form of lipids to physiological responses through the activation of metabolic target genes. Due to their key roles in lipid and carbohydrate metabolism, the PPARs are important drug targets. However, for several of the PPAR drugs currently in use, adverse side effects have been reported. In an effort to identify compounds from marine organisms that may serve as molecular scaffolds for the development of novel and safer PPAR-targeting drugs, we performed a bioassay-guided screening of organic extracts made from organisms supplied by the Norwegian Biobank of Arctic Marine Organisms (Marbank). Among several interesting hits, we identified two poorly described isomeric oxo-fatty acids from the microalgae Chaetoceros karianus for which we provide the first evidence that they might display dual specificity towards human $\operatorname{PPAR} \alpha$ and PPAR $\gamma$. Principal component analysis showed that C. karianus stood out from other Chaetoceros species, both with respect to the metabolic profile and the PPAR activity. The isolation of these compounds holds the potential of uncovering a PPAR pharmacophore with tunable activity and specificity.
\end{abstract}

Keywords: PPAR; dual agonist activity; metabolomics; Chaetoceros karianus; LC-MS ; NMR

\section{Introduction}

The peroxisome proliferator-activated receptors (PPARs) are operating as lipid sensing receptors at the crossroads between carbohydrate and lipid homeostasis, and metabolic disorders. Functioning as ligand-activated transcription factors, they integrate signals in the form of lipids (fatty acids, phospholipids, eicosanoids, and other oxygenated fatty acids) to physiological responses through the activation of metabolic target genes [1,2]. A first step in this process is the binding of lipid ligands to the PPAR ligand-binding domain (LBD) $[3,4]$. In humans, the PPAR isoforms PPAR $\alpha$ and $-\gamma$ are mainly expressed in liver and adipose tissue, respectively, while PPAR $\delta$ is more ubiquitously 
expressed [1,5]. When PPAR $\gamma$ is ligand-activated it induces adipocyte growth and differentiation by transcriptionally regulating target genes involved in lipogenesis and lipid storage [6-8]. Moreover, the activation of PPAR $\gamma$ maintains normal insulin sensitivity through upregulation and secretion of adipokines such as adiponectin and leptin from adipose tissue [9]. In parallel, PPAR $\alpha$ increases lipid uptake and energy expenditure in the liver by upregulating targets involved in fatty acid transport, activation, and oxidation $[10,11]$. Altogether this protects the organism against high levels of circulating triacylglycerols and harmful free fatty acids [12] and ensures normal insulin function in peripheral tissues [9]. However, when adipose tissue increases past critical mass, it attracts immune cells like NK cells and macrophages, and starts to secrete pro-inflammatory cytokines like tumor necrosis factor alpha (TNF- $\alpha$ ), interleukin- 1 beta (IL-1 $\beta$ ), and resistin, which results in suppressed insulin action and increased low density lipoprotein (LDL)-cholesterol [13-16]. Liver steatosis is another detrimental condition, fueled by PPAR $\gamma$ during a high-fat state [17]. This leads to reduced fatty acid oxidation and ultimately liver failure, which together with the adverse adipokine secretion exacerbates obesity.

With their key roles in lipid and sugar metabolism, the PPARs have for many years been top priority drug targets [18]. Consequently, several PPAR ligands with well-recognized biological effects are in clinical use, like the hypolipidemic fibrates, acting as PPAR $\alpha$ activators, and the anti-diabetic thiazolidinediones (TZDs), targeting PPAR $\gamma[19,20]$. However, adverse side effects have been reported, especially for the TZDs [21,22]. One way to avoid these problems has been to find or design partial $[23,24]$ or dual $[25,26]$ agonists which in general seems to come with fewer side effects. Thus, the aim of the present work was to identify compounds from marine organisms that regulate PPAR activity, and that may serve as molecular scaffolds for the development of novel, safer PPAR-targeting drugs.

The diatom genus Chaetoceros contributes heavily to the overall primary production in the northern and Arctic seas $[27,28]$. Northern diatoms are characterized by potentially high chemical diversities and bioactivity levels $[29,30]$. Several species from this genus, kept in stock cultures by the Norwegian Biobank of Arctic Marine Organisms (Marbank, www.imr.no/marbank/en), were used as a library in the bioassay-guided screening for PPAR ligands reported herein. In the present study we identified two poorly described, closely related oxo-fatty acids (Figure 1) from the diatom Chaetoceros karianus with an apparent dual specificity towards human PPAR $\alpha$ and PPAR $\gamma$. The isolation of these isomeric compounds with dual PPAR $\alpha / \gamma$ agonist activity holds the potential of uncovering a pharmacophore with tunable activity and specificity.
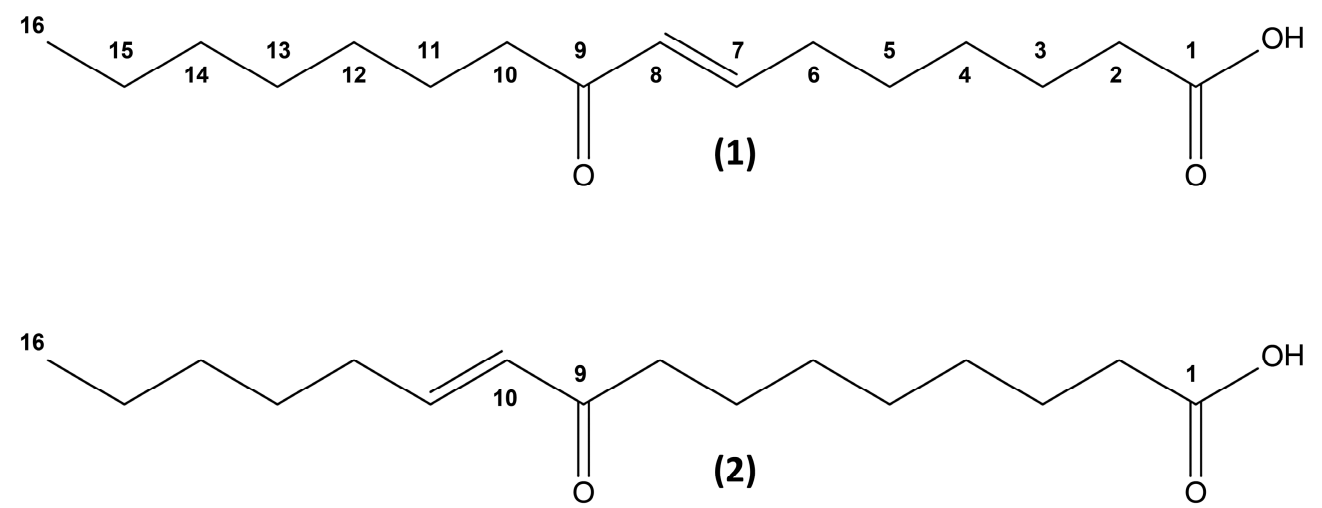

Figure 1. Chemical structures of the two isolated oxo-fatty acids, (7E)-9-oxohexadec-7-enoic acid (1) and (10E)-9-oxohexadec-10-enoic acid (2).

\section{Results and Discussion}

The main goal of this study was to identify novel PPAR agonists or modulators from arctic marine organisms. Any such hit compound might later form the basis of a structure-activity-relationship (SAR) effort, where the aim would be to develop drugs for the treatment of diabetes and metabolic syndrome. To this end, we performed a primary screening where we transiently expressed Gal4-LDB 
constructs comprising the ligand binding domain (LBD) of human PPAR $\alpha,-\gamma$, and $-\delta$ fused to the yeast Gal4 DNA-binding domain in COS-1 cells, a fibroblast-like cell line derived from monkey (Cercopithecus aethiops) kidney. Testing of hundreds of extracts $(40 \mathrm{mg} / \mathrm{mL})$ from Marbank in the cell assay system allowed us to identify and confirm the PPAR modulatory activity from a diverse set of organisms (Table S1). The diatom species Chaetoceros karianus (M11031) interestingly showed a consistent activation of PPAR $\alpha$ and $-\gamma$. Importantly, the same extracts were not able to activate human PPAR $\delta$, or human Liver X receptor (LXR) $\alpha$ or $-\beta$ (not shown).

To verify the findings from $C$. karianus, Flash chromatography fractions of fresh materials from the Marbank were prepared as described in the experimental section by reconstituting organic extracts in $\mathrm{ACN} / \mathrm{H}_{2} \mathrm{O}$, defatting with hexane, reconstituting in $\mathrm{ACN} / \mathrm{H}_{2} \mathrm{O}$, and eluting from a reverse-phase C18 solid phase extraction (SPE) column. The new eluates $(100 \mathrm{mg} / \mathrm{mL})$ were used to stimulate COS-1 cells, this time expressing full-length human PPAR $\alpha$ or $-\gamma$ together with retinoic acid X receptor alpha $(\mathrm{RXR} \alpha)$, the natural PPAR heterodimerization partner. Gene activation was assessed on Luciferase reporters driven by natural promoters; human CPTA1 for PPAR $\alpha$ and human PLIN1 for PPAR $\gamma$. As demonstrated (Figure 2A,B), the $C$. karianus extract was able to activate both promoters. When using reporters with mutated PPAR recognition elements (PPREs), the extract's ability to activate was significantly reduced (Figure 2C,D), corroborating PPAR-dependent agonism.

A

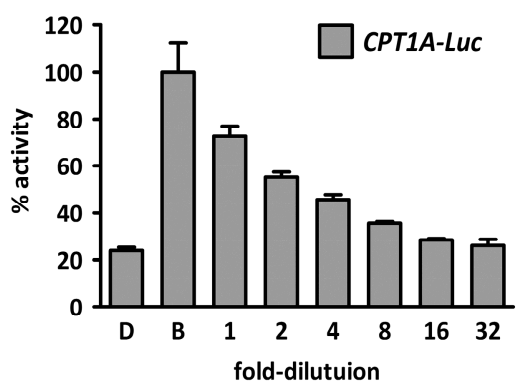

C

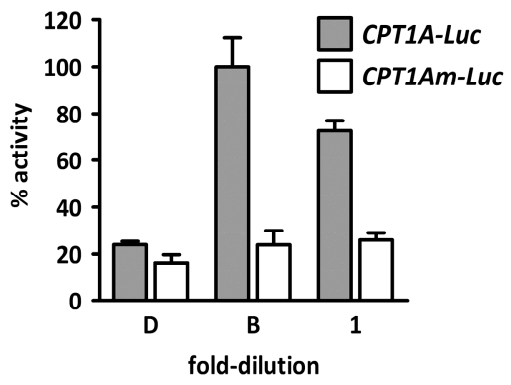

B

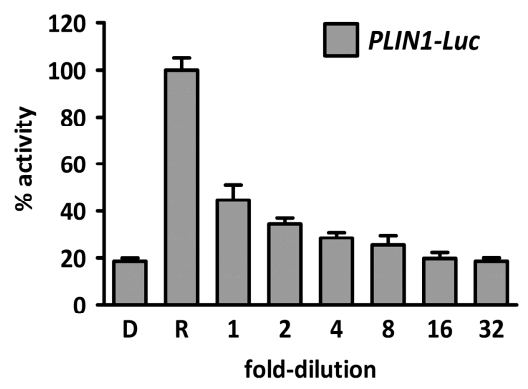

D

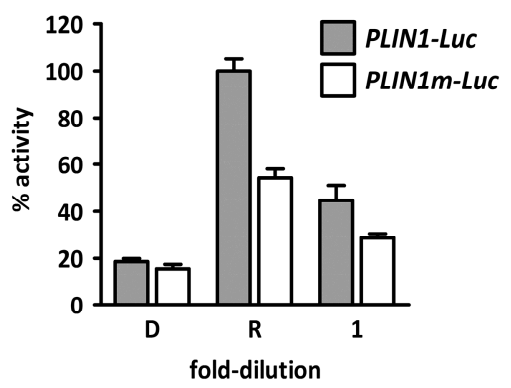

Figure 2. Concentration-dependent activation of natural peroxisome proliferator-activated receptor (PPAR) target gene promoters using solid phase extraction (SPE) eluates from Chaetoceros karianus. Monkey kidney fibroblasts, COS-1 cells, were transfected with plasmids expressing human, full-length $\operatorname{PPAR} \alpha$, retinoic acid $\mathrm{X}$ receptor alpha $(\mathrm{RXR} \alpha)$, and a CPT1A promoter-driven luciferase reporter (A) or with a CPT1A reporter with PPAR response elements (PPREs) mutated (C). Correspondingly, cells were transfected with plasmids expressing human, full-length PPAR $\gamma$ and RXR $\alpha$ and a PLIN1 promoter-driven luciferase reporter (B) or with a PLIN1 reporter with PPREs mutated (D). Cells were treated with a dilution series of SPE eluates $(100 \% \mathrm{ACN})$. 1:1 dilution corresponds to $\sim 100 \mu \mathrm{g}$ dry weight $/ \mathrm{mL}$. The results represent mean relative light units (RLU) \pm s.d. of two independent assays performed in duplicate. The activities of the positive controls (Rosiglitazone or Bezafibrate) were set to 100\%. D: DMSO, B: $50 \mu$ M Bezafibrate, R: $1.0 \mu$ M Rosiglitazone. 
In order to track the activity found in the extract, we developed a HPLC-based activity profiling protocol (see Experimental section). The chromatogram (210-600 nm) of a semi-preparative HPLC separation (1.25 g extract) and the corresponding activity profile of the time-based fractionation (40 fractions of $60 \mathrm{~s}$ each) is shown in Figure 3A. The activity was found in the fractions collected between 14 and $22 \mathrm{~min}$ (Figure 3A). The pooled fractions of several injections were concentrated and a second semi-preparative HPLC separation based on peak signal absorption at $227 \mathrm{~nm}$ was applied (Figure 3, insert). The major peak of activity was found in fractions 10, 11, and 12 (Figure 3B,C). A dual, yet weakly isoform-specific, agonist activity profile was observed, where fractions 10 and 11 increased PPAR $\alpha$ activation over the solvent controls by 224 and 167\%, respectively, and fractions 10, 11, and 12 increased PPAR $\gamma$ activation by 175,388 , and $211 \%$, respectively. All the remaining fractions showed minimal activity and were not considered further.
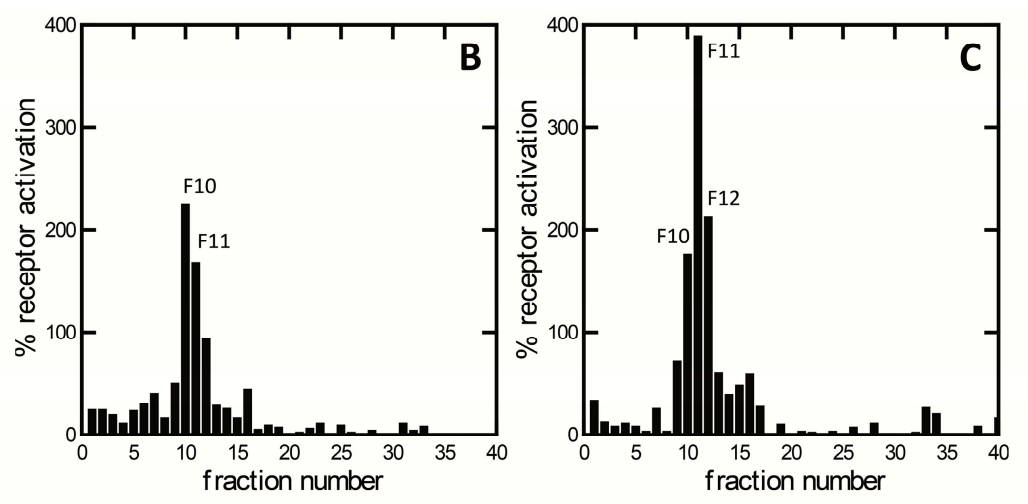

A

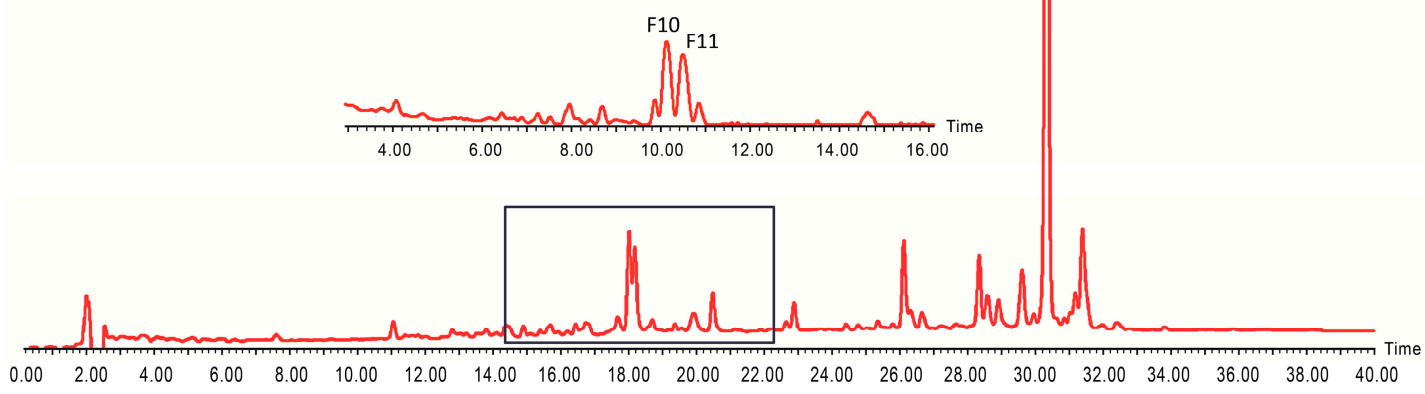

Figure 3. HPLC-based PPAR activity profiling of an acetonitrile $/ \mathrm{H}_{2} \mathrm{O}$ extract of Chaetoceros karianus. Panel (A) shows a representative HPLC chromatogram $(210-600 \mathrm{~nm}$ ) of a semi-preparative separation of $1.2 \mathrm{~g}$ microalgal extract. The activity was initially found in the squared area in the time-based fractionation. The insert shows part of a peak-based separation for final purification. The HPLC-based activity profiling for PPAR $\alpha(\mathbf{B})$ and PPAR $\gamma(\mathbf{C})$ receptor modulatory activity are shown above the chromatogram. The activities of the positive controls (Rosiglitazone or Bezafibrate) were set to $100 \%$.

Isolation of the two active compounds, 1 and 2, was achieved by reverse-phase SPE and subsequent purification with semi-preparative HPLC. The compounds were tracked with the aid of ultra-performance liquid chromatography-electrospray tandem mass spectrometry (UPLC-ESIMS) and photodiode array detection (UPLC-PDA). In Figure 4A,B, typical base peak chromatograms of an SPE eluate, acquired in both positive and negative mode, are shown. The defatting step with hexane removed apolar lipids that might interfere with our screening system, while the SPE step was designed to retain polar molecules and peptides, which were not of interest in our nuclear receptor screen, as they translocate poorly to the cell nucleus and rarely have been reported to activate PPARs. As shown in Figure 4A,B, the isolated compounds ionize differently in positive and negative mode and appeared to not be the main components of the fraction mixture based on MS signal intensities. 

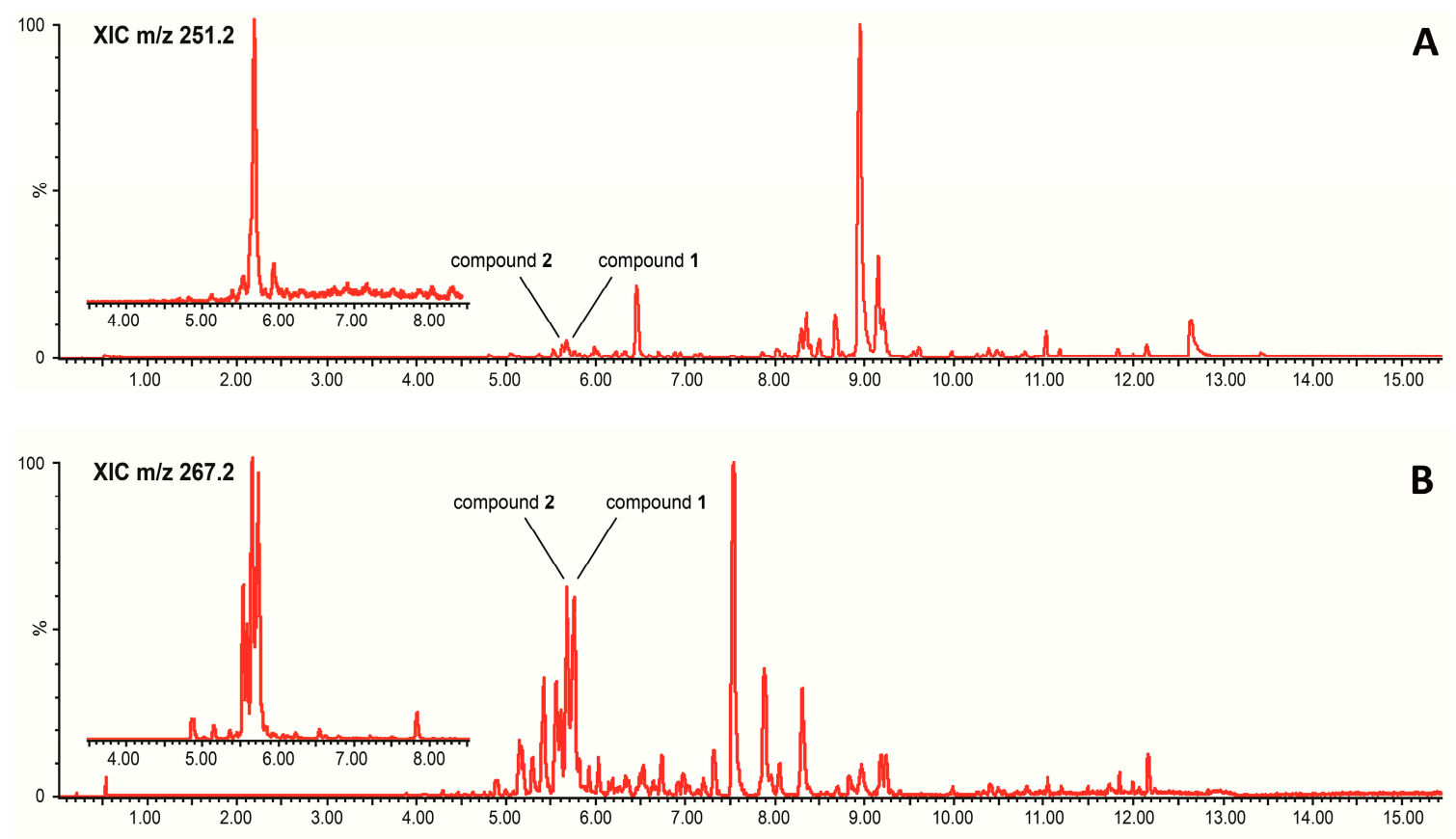

Figure 4. Ultrahigh performance liquid chromatography-electrospray ionization base peak chromatograms of a solid phase extraction (SPE) eluate generated from culture extracts of Chaetoceros karianus in (A) positive mode (UPLC-ESI ${ }^{+}$) and (B) negative mode (UPLC-ESI ${ }^{-}$). Insert: Extracted ion chromatograms of the most intense ions, $m / z 251.2\left[\mathrm{M}+\mathrm{H}-\mathrm{H}_{2} \mathrm{O}\right]^{+}$in positive mode (A) and $m / z 267.2$ $[\mathrm{M}-\mathrm{H}]^{-}$in negative mode (B).

High-resolution mass spectrometry (HRMS) was used to identify the molecular weight and thus the molecular composition of the isolated compounds. Initial studies in positive ionization mode showed complex mass spectra for compounds $\mathbf{1}$ and $\mathbf{2}$, indicating that it was advantageous to apply both positive and negative mode ionization protocols. Upon positive ESIMS, ions tentatively identified as $[\mathrm{M}+\mathrm{H}]^{+}(\mathrm{m} / \mathrm{z} 269.2114$ for $1 ; \mathrm{m} / z 269.2116$ for 2$)$, as well as more prominent ions attributable to sodium addition $\left([\mathrm{M}+\mathrm{Na}]^{+}\right)$and dehydration $\left(\left[\mathrm{M}+\mathrm{H}-\mathrm{H}_{2} \mathrm{O}\right]^{+},\left[\mathrm{M}+\mathrm{H}-2 \mathrm{H}_{2} \mathrm{O}\right]^{+}\right)$, were observed (data no shown). In addition, diagnostic ions corresponding to $[\mathrm{M}+\mathrm{H}-46]^{+}$attributable to the loss of $\mathrm{CH}_{2} \mathrm{O}_{2}$ indicated the presence of a carboxylic group in the two molecules. Further studies applying negative ionization mode afforded predominantly ions corresponding to $[\mathrm{M}-\mathrm{H}]^{-}(\mathrm{m} / \mathrm{z} 267.1966$ for 1 and 2), thus confirming the identity of the $[\mathrm{M}+\mathrm{H}]^{+}$ion. This allowed us to determine the molecular formula of the two compounds, which turned out to be $\mathrm{C}_{16} \mathrm{H}_{28} \mathrm{O}_{3}$ for both molecules, showing that they were structural isomers with a number of ring double bond equivalents of three.

The two isomers were subsequently determined as (7E)-9-oxohexadec-7-enoic acid (1) and (10E)-9-oxohexadec-10-enoic acid (2) from the interpretation of one- and two-dimensional NMR data as well as HRMS and HRMS/MS spectra. Furthermore, the structure determination process was assisted by database searches (Dictionary of Marine Natural Products, www.chemnetbase.com).

The compounds were isolated as colorless oils in quantities of $60 \mu \mathrm{g}$ of compound 1 (approx. 95\% purity) and $53 \mu \mathrm{g}$ of compound 2 (approx. 75\% purity). The UV spectra of both compounds were similar with a single absorption maximum $\left(\lambda_{\max }\right)$ at $227 \mathrm{~nm}(\mathbf{1})$ and $226 \mathrm{~nm}(2)$ indicating the absence of conjugation. The HRMS/MS spectra of the two structural isomers exhibited several features that were of high diagnostic value. Most notably, fragment ions with $m / z$ corresponding to [M - H $44]^{-}$upon negative ionization and $[\mathrm{M}+\mathrm{H}-46]^{+}$upon positive ionization are commonly a result of the loss of $\mathrm{CO}_{2}$ and $\mathrm{CH}_{2} \mathrm{O}_{2}$, respectively, and indicated the presence of a carboxylic acid (Figure 5). Furthermore, the MS/MS spectra contained a series of ions typical for hydrocarbons $(m / z 71,85,99)$, and thus gave strong evidence for compounds $\mathbf{1}$ and $\mathbf{2}$ being fatty acid derivatives. The major fragment 
ions, however, were observed at $\mathrm{m} / \mathrm{z} 127.1339$ for 1 and $\mathrm{m} / \mathrm{z} 123.1038$ and 125.1191 for 2 (Figure 5), indicating a structural feature in the central part of the hydrocarbon backbone that facilitates the breakage of one or more covalent bonds.
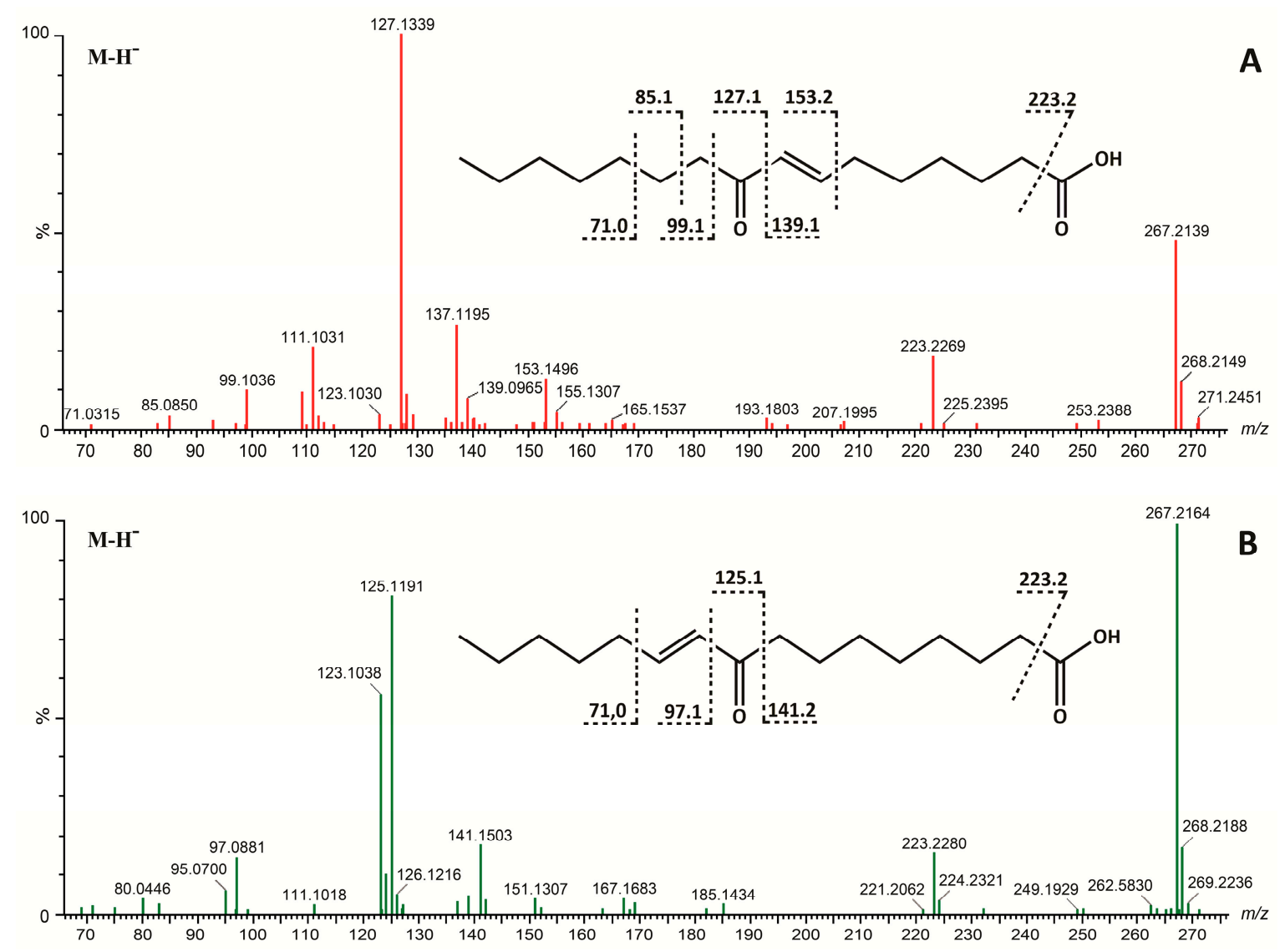

Figure 5. High-resolution mass spectrometry (HRMS/MS) spectra from fragmentations of $[\mathrm{M}-\mathrm{H}]^{-}$ ions of (A) (7E)-9-oxohexadec-7-enoic acid ( $\mathrm{m} / \mathrm{z}$ 267.2139), (B) (10E)-9-oxohexadec-10-enoic acid $(\mathrm{m} / \mathrm{z}$ 267.2164) and the assigned structurally informative fragmentations of these ions.

Detailed analyses of one- and two-dimensional NMR data, including ${ }^{1} \mathrm{H}$, correlation spectroscopy (COSY), total correlation spectroscopy (TOCSY), selective TOCSY (SELTOCSY), gradient-selected heteronuclear single quantum coherence spectroscopy (g-HSQC), gradient-selected heteronuclear multiple bond correlation (g-HMBC), HSQC-TOCSY, and nuclear overhauser effect spectroscopy (NOESY) spectra determined in $\mathrm{CD}_{3} \mathrm{CN}$ as well as the comparison with published spectral data [31,32], afforded complete ${ }^{1} \mathrm{H}$ and ${ }^{13} \mathrm{C}$ assignments for compounds $\mathbf{1}$ and $\mathbf{2}$ (Table 1). The data showed the presence of a trans-coupled $\left({ }^{3} \mathrm{~J}_{\mathrm{H}-\mathrm{H}}=15.9 \mathrm{~Hz}\right)$ pair of olefinic protons at $6.08 / 6.84 \mathrm{ppm}$ in $\mathbf{1}$ and 6.08/6.85 ppm in 2. In both isomers the lower-field olefinic proton (i.e., $6.84 \mathrm{ppm}$ and $6.85 \mathrm{ppm}$ ) was additionally coupled $\left({ }^{3} \mathrm{~J}_{\mathrm{H}-\mathrm{H}}=7.0 \mathrm{~Hz}\right)$ to a methylene proton resonance at $2.22 \mathrm{ppm}$, while the higher-field olefinic proton (i.e., $6.08 \mathrm{ppm}$ ) only showed weak ${ }^{4} J_{\mathrm{H}-\mathrm{H}}$ coupling $(1.5 \mathrm{~Hz})$ to the same methylene protons, but no ${ }^{3} J_{\mathrm{H}-\mathrm{H}}$ coupling in addition to its olefinic neighbor. At the same time, the g-HMBC spectra showed the presence of a carboxyl-carbon at $175.0 \mathrm{ppm}$ (1) and $175.2 \mathrm{ppm}$ (2), as well as a carbonyl-carbon at 201.4 ppm (identical shift for both compounds). 
Table 1. ${ }^{1} \mathrm{H}$ and ${ }^{13} \mathrm{C}$ NMR data of compounds 1 and $2\left(600 / 150 \mathrm{MHz}\right.$ in $\mathrm{CD}_{3} \mathrm{CN}, \delta$ in ppm, J in $\left.\mathrm{Hz}\right)$.

\begin{tabular}{ccccc}
\hline \multirow{2}{*}{ Position } & \multicolumn{3}{c}{$\mathbf{1}^{\mathbf{a}}$} & \multicolumn{2}{c}{$\mathbf{2}^{\mathbf{a}}$} \\
\cline { 2 - 5 } & ${ }^{\mathbf{1 3}} \mathbf{C}$ & ${ }^{\mathbf{1}} \mathbf{H}$ & ${ }^{\mathbf{3}} \mathbf{C}$ & ${ }^{\mathbf{1}} \mathbf{H}$ \\
\hline 1 & $175.0, \mathrm{t}$ & - & $175.2, \mathrm{t}$ & - \\
2 & $34.2, \mathrm{t}$ & $2.27, \mathrm{t},(7.4)$ & $34.3, \mathrm{t}$ & $2.27, \mathrm{t},(7.5)$ \\
3 & $25.6, \mathrm{t}$ & $1.57, \mathrm{~m}$ & $25.6, \mathrm{t}$ & $1.57, \mathrm{~m}$ \\
4 & $29.5, \mathrm{t}$ & $1.34, \mathrm{~m}$ & $29.8, \mathrm{t}$ & $1.31, \mathrm{~m}$, overlapped \\
5 & $28.7, \mathrm{t}$ & $1.48, \mathrm{~m}$ & $29.8, \mathrm{t}$ & $1.31, \mathrm{~m}$, overlapped \\
6 & $33.0, \mathrm{t}$ & $2.22, \mathrm{ddt},(7.5,7.0,1.5)$ & $29.8, \mathrm{t}$ & $1.31, \mathrm{~m}$, overlapped \\
7 & $148.2, \mathrm{~d}$ & $6.84, \mathrm{dt},(15.9,7.0)$ & $25.1, \mathrm{t}$ & $1.55, \mathrm{~m}$ \\
8 & $131.1, \mathrm{~d}$ & $131.1, \mathrm{dt},(15.9,1.5)$ & $40.4, \mathrm{t}$ & $2.54, \mathrm{t},(7.4)$ \\
9 & $201.4, \mathrm{~s}$ & - & $201.4, \mathrm{~s}$ & - \\
10 & $40.4, \mathrm{t}$ & $2.54, \mathrm{t},(7.4)$ & $131.2, \mathrm{~d}$ & $6.08, \mathrm{dt},(15.9,1.5)$ \\
11 & $25.1, \mathrm{t}$ & $1.55, \mathrm{~m}$ & $148.1, \mathrm{~d}$ & $6.85, \mathrm{dt},(15.9,7.0)$ \\
12 & $29.8, \mathrm{t}$ & $1.30, \mathrm{~m}$ & $33.0, \mathrm{t}$ & $2.22, \mathrm{ddt} .(7.5,7.0,1.5)$ \\
13 & $30.4, \mathrm{t}$ & $1.29, \mathrm{~m}$ & $28.6, \mathrm{t}$ & $1.48, \mathrm{tt},(7.5,7.5)$ \\
14 & $32.5, \mathrm{t}$ & $1.30, \mathrm{~m}$ & $32.2, \mathrm{t}$ & $1.33, \mathrm{~m}$ \\
15 & $23.3, \mathrm{t}$ & $1.32, \mathrm{~m}$ & $23.3, \mathrm{t}$ & $1.34, \mathrm{~m}$ \\
16 & $14.4, \mathrm{q}$ & $0.90, \mathrm{t},(7.0)$ & $14.4, \mathrm{q}$ & $0.91, \mathrm{t},(7.0)$ \\
\hline
\end{tabular}

a chemical shifts, determined at $25^{\circ} \mathrm{C}$, are relative to internal $\mathrm{CHD}_{2} \mathrm{CN}(1.96 \mathrm{ppm})$ and $\mathrm{CD}_{3} \mathrm{CN}$ (118.26 ppm) [33].

The quantity of the isolated material was too low to obtain one-dimensional direct ${ }^{13} \mathrm{C}-\mathrm{NMR}$ data, and the DEPT spectra only showed few ${ }^{13} \mathrm{C}$-resonances of low signal/noise. The carbonyl-carbon showed ${ }^{2} \mathrm{~J}_{\mathrm{C}-\mathrm{H}}$ and ${ }^{3} \mathrm{~J}_{\mathrm{C}-\mathrm{H}}$ correlations in the g-HMBC spectra to a ${ }^{3} \mathrm{~J}_{\mathrm{H}-\mathrm{H}}$ coupled methylene proton resonance at $2.54 \mathrm{ppm}$ (identical shift for both compounds) and the lower-field olefinic proton, respectively. From these data it became clear that the carbonyl-function was interspersed between the olefinic double bond and an aliphatic chain, i.e., the compounds contained an $\alpha, \beta$-unsaturated ketone. For further structure determination of compound 1, the assessment of the g-HSQC, g-HMBC, and high-resolution COSY data clearly showed the presence of five methylene groups between the carboxyl-carbon and the olefinic moiety, i.e., the molecule contained a 7,8-double bond. The exact assignment of the methylene groups between the C-9 carbonyl and the terminal methyl group was ambitious, as the protons of five of the six methylene groups appeared in a narrow window between $1.29 \mathrm{ppm}$ and $1.32 \mathrm{ppm}$. Using high-resolution COSY data, it was possible to identify four of the six methylene groups. Assignment of the remaining two methylene groups was only possible using the HSQC-TOCSY experiment. This is a hybrid experiment that gives through-bond correlations between ${ }^{a}{ }^{13} \mathrm{C}$-attached proton to all other coupled protons. The coupled protons can be seen along a line at the same ${ }^{13} \mathrm{C}$ chemical shift from the carbon atom attached to the primary proton (i.e., the HSQC crosspeak). The assignment of the remaining methylene groups was then possible because individual methylene groups were well resolved in the ${ }^{13} \mathrm{C}$ dimension even though they overlapped in the ${ }^{1} \mathrm{H}$ dimension. NMR assignment of compound 2 started at the terminal methyl group. Long-range TOCSY data (mixing time parameter $\mathrm{d} 9=160 \mathrm{~ms}$ ) showed a correlation between the methyl protons and the olefinic protons, and hence these protons belonged to a common ${ }^{1} \mathrm{H}$ spin system. Such a correlation was absent in a TOCSY spectrum acquired using a mixing time of $80 \mathrm{~ms}$. The assignment of the methylene groups between the terminal methyl and the olefinic moiety was in this case ambitious due to the fact that the NMR sample of compound 2 contained about $25 \%$ of compound 1 . However, careful examination of the g-HMBC, g-HSQC, SELTOCSY, and COSY data starting from the terminal methyl group showed that compound 2 contained a 10,11-double bond, while the carbonyl group was at the same position as in $\mathbf{1}$.

Mass spectrometry-aided structural elucidation of $\mathbf{1}$ and $\mathbf{2}$ was performed by interpreting HRMS and HRMS/MS analyses of the isolated compounds (Figure 5). Compound 1 showed a fragmentation pathway leading to an intense $[\mathrm{M}-140]^{-}$fragment ion apparent at $m / z 127.1339$ (Figure 5A). This ion is consistent with $\alpha$-cleavage of the ketone across $\mathrm{C} 8-\mathrm{C} 9$, i.e., the bond joining the olefinic moiety in 
position C7-C8 with the carbonyl group at C9. Other minor fragments observed could be ascribed to cleavage in activated sites within the aliphatic skeleton. The fragment ion at $m / z 139.0935[\mathrm{M}-128]^{-}$ is likewise consistent with cleavage across the C8-C9 bond, but with the charge on the other part of the molecule (Figure 5A). The fragment ion at $m / z 137.1195$ could be explained by oxidation of the double bond at the fragment ion $\mathrm{m} / \mathrm{z} 139.0935$ (Figure 5A). The location of the keto group in C-9 is confirmed by the presence of the ion $m / z$ 99.1036, consistent with $\alpha$-cleavage of the ketone across the C9-C10 bond. Other fragment ions of interest are $m / z$ 85.1, consistent with a $\beta$-cleavage at the C10-C11 bond and the fragment ion at $m / z 153.1496[\mathrm{M}-114]^{-}$, which could be ascribed to a cleavage of the bond adjacent to the double bond at C7-C8 (Figure 5A). Another fragment ion observed at $m / z 223.2269[\mathrm{M}-44]^{-}$could $^{-}$ be ascribed to the loss of $\mathrm{CO}_{2}$, which is diagnostic for carboxylic acids such as fatty acids and fatty acid derivatives. Compound $\mathbf{2}$ showed similar fragmentation pathways as compound $\mathbf{1}$ (Figure 5B), with typical $\alpha$-cleavages observed in oxo-fatty acids [34]. An intense fragment ion at $m / z 125.1191$ was consistent with cleavage across C8-C9 (Figure 5B). Other important product ions were observed at $m / z$ $97.0881[\mathrm{M}-170]^{-}$, consistent with $\alpha$-cleavage to the keto group across C9-C10, and the diagnostic ion at 223.2280 [M -44$]^{-}$, consistent with the loss of $\mathrm{CO}_{2}$ (Figure $5 \mathrm{~B}$ ). The prominent $\mathrm{m} / \mathrm{z} 123.1038$ product ion in the product ion spectrum of 2 could be the result of water loss from $\mathrm{m} / \mathrm{z} 141.1503$ (Figure 5B).

As hypothesized, based on the dereplication described above, the isolated compounds turned out to be 9-oxohexadec-7-enoic acid (oxo-FA 1) (Figures 1 and 5A) and 9-oxohexadec-10-enoic acid (oxo-FA 2) (Figures 1 and 5B). After establishing the structures of the two molecules 1 and 2, comprehensive literature searches revealed that the (E)-isomers of these molecules had recently been described from other marine organisms [31,32]. In 2005 a new $C_{16}$ fatty acid-based oxylipin pathway was demonstrated in axenic cultures of the diatom Thalassiosira rotula, and compound 1 was isolated along with other novel oxo- and hydroxy unsaturated fatty acids, but no biological activity was reported [31]. Compound 2 was isolated in a later study aimed at identifying natural products with anti-inflammatory activity from the red algae Gracilaria verrucosa [32]. Compound 2 significantly inhibited the production of the pro-inflammatory mediators NO and IL-6 in lipopolysaccharide-activated murine macrophage cells [32].

Having refined the oxo-fatty acids $\mathbf{1}$ and $\mathbf{2}$ to approximately 95\% and 75\% purity, respectively, we wanted to reevaluate the weak PPAR isoform specificity observed during the bioassay-guided isolation. To this end we treated COS-1 cells expressing Gal4-LBD chimeras with $100 \mu \mathrm{M}$ of $\mathbf{1}$ and 2. As can be seen in Figure 6, the dual PPAR $\alpha / \gamma$ specificity profile was retained, while the potency was somewhat reduced. Still, oxo-FA 1 seems to activate PPAR $\gamma$ slightly better than oxo-FA 2 (Figure 6B), while the opposite is true for PPAR $\alpha$ (Figure 6A). The low amount of material isolated (60 $\mu \mathrm{g}$ and $53 \mu \mathrm{g}$ of oxo-FA1 and oxo-FA2, respectively) prevented further pharmacological characterization of the two compounds. In a follow-up study, we intend to characterize the dose-response curves of these oxo-fatty acids with respect to PPAR $\alpha / \gamma$ binding and confirm the functional activation of these receptors by studying their PPAR-dependent regulation of relevant, endogenous target genes.

With their dual PPAR $\alpha / \gamma$ specificity, these oxo-fatty acids might make a good start for a structure-activity-relationship (SAR) study to identify PPAR-targeting anti-diabetic drug leads. This could be achieved by comparing our oxo-fatty acids ( $\mathbf{1}$ and 2 ) with other cis- and trans-hexadecenoic acids that do not possess the carbonyl group in their structure. Moreover, the activity profile of the C. karianus oxo-fatty acids, as well as derivatives thereof, should be compared with the profile of other promising dual PPAR $\alpha / \gamma$ agonists, like Saroglitazar [35]. Saroglitazar is marketed in Asia and displays significant improvement in both glycemic as well as dyslipidemic parameters with no evidence of conventional side effects (as reviewed in [25]). From a structural perspective, a recent study by Yore et al. [36] who made use of quantitative MS to identify metabolic changes in transgenic Glut4 mice is highly interesting. Despite being obese, the studied animals showed an increased glucose tolerance. Lipidomic analysis of their adipose tissue revealed the existence of branched fatty acid esters of hydroxy fatty acids, so called FAHFAs. The most abundant form both in mice and human white and brown adipose tissue is 9-PAHSA (palmitic acid-hydroxy stearic acid), 
having the hydroxyl/ester group placed on the same carbon as our 9-oxo-FAs. Even though the PAHSAs signal through GPR120 to enhance insulin-stimulated glucose uptake, it could be possible that the corresponding unbranded fatty acids (with the hydroxy-/keto group on C9) might have equally beneficial effects with regard to whole body insulin sensitivity when functioning as PPAR agonists.

A

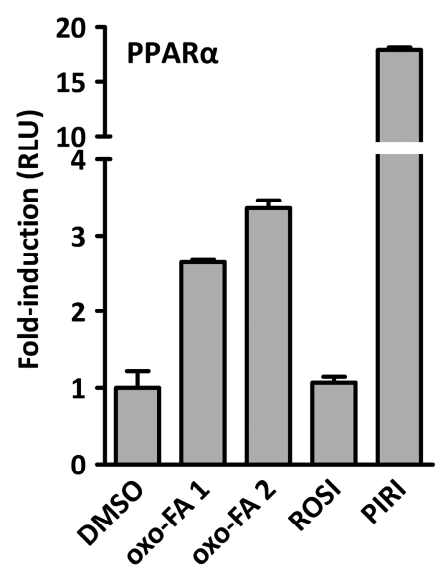

B

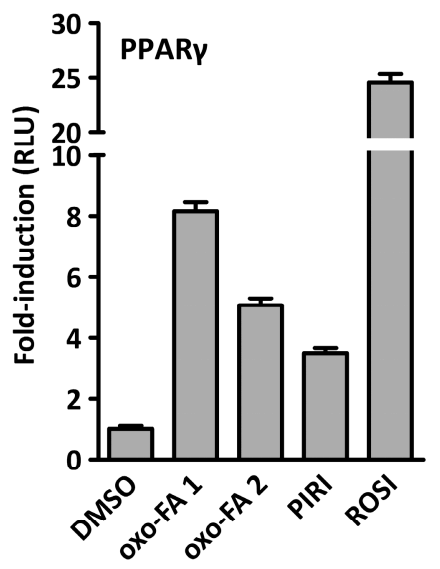

Figure 6. Dual PPAR $\alpha / \gamma$ agonist activity with limited isoform specificity. COS-1 cells transfected with a $5 \times$ upstream activating sequence $(5 \times \mathrm{UAS})$-driven luciferase reporter and (A) plasmids expressing yeast Gal4 DNA-binding fused to the ligand binding domain (LBD) of human PPAR $\alpha$ (Gal4-PPAR $\alpha$-LBD) or (B) PPAR $\gamma($ Gal4-PPAR $\gamma$-LBD) were treated with $100 \mu \mathrm{M}$ (7E)-9-oxohexadec-7-enoic acid (oxo-FA 1), $100 \mu \mathrm{M}$ (10E)-9-oxohexadec-10-enoic acid (oxo-FA 2), $1 \mu \mathrm{M}$ Rosiglitazone (ROSI; PPAR $\gamma$ agonist), or $100 \mu \mathrm{M}$ pirinixic acid (PIRI; PPAR $\alpha$ agonist). The results represent the mean RLU \pm s.d. of two independent assays performed in quadruplicate.

Finally, to address whether the identified metabolite/activity profile is unique to the planktonic diatom Chaetoceros karianus, we employed a metabolomics approach to compare it with different, but related microalgae. Four additional strains of species belonging to the genus Chaetoceros were obtained from the Marbank collection. Extracts and SPE eluates were generated from Cheatoceros decipiens (M09048), Chaetoceros diadema (M09047), Chaetoceros furcellatus (M08023), Chaetoceros karianus (M11031), and Chaetoceros socialis (M08009) as described in the Experimental section. To assess the analogies and differences in the composition of the metabolites of the five species, a non-targeted metabolite fingerprinting of SPE eluates was conducted. $\mathrm{ACN} / \mathrm{H}_{2} \mathrm{O}$-soluble constituents from these species were analyzed by UPLC-HRESIMS as described in the Experimental Section. Results from the UPLC-HRESIMS were further processed by peak picking and alignment for further Principle Components Analyses (PCA). PCA demonstrated that striking differences exist between the metabolic profiles of the five Chaetoceros species (Figure 7). Interestingly, the most distinct profiles were those obtained from C. karianus and C. diadema.

When data obtained by UPLC-HRESIMS in positive ionization mode were subjected to principal component analysis (PCA) (Figure 7A), it appeared that $C$. furcellatus and C. decipiens are similar with regard to metabolite production. In positive ionization mode, the replicates were perfectly clustered, indicating an appropriate method repeatability. Negative ionization mode data showed similar clustering (Figure 7B), but in this case C. furcellatus and C. socialis were almost overlapping. Both in positive and negative mode, it appeared that the metabolic profiles of C. furcellatus, C. decipiens, and C. socialis were closely related. On the other hand C. karianus and C. diadema were less related to the other three species and to each other with regard to metabolite production. In negative ionization mode, the replicates were not as well clustered as in positive mode and showed some deviation (Figure 7B). This somehow lower reproducibility could be attributed to instrumental drift and injection 
problems. Interestingly, and in line with the different metabolic profiles, the different Chaetoceros extracts displayed different PPAR $\alpha / \gamma$ agonist activity (Figure 7C). Even though the relative position of the species was shifted, the C. karianus PPAR $\alpha / \gamma$ activity was found to be high and at a distance from both C. furcellatus and C. socialis, and C. diadema and C. decipiens which seemed to be more closely related, respectively. Whether this is due to differences in oxo-fatty acid levels or different levels of related or unrelated metabolites is not known and should be addressed in future studies.

A

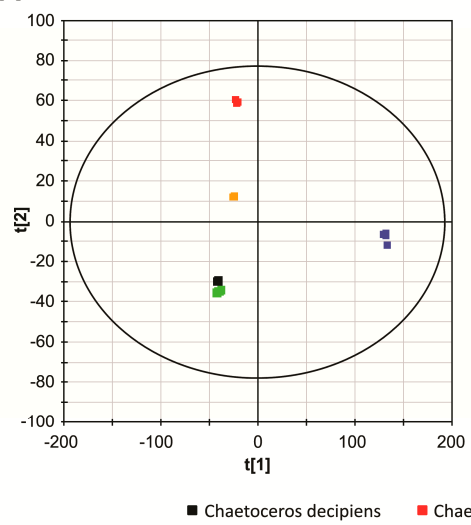

B

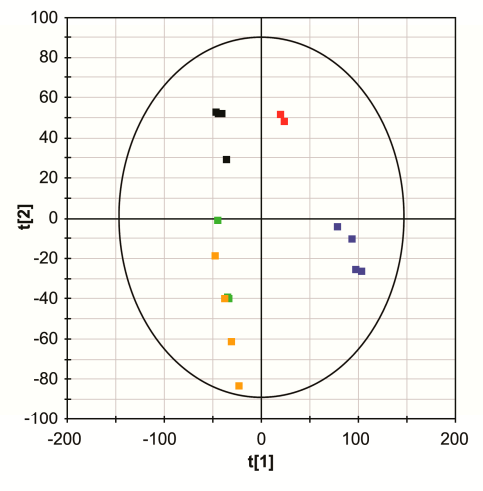

C

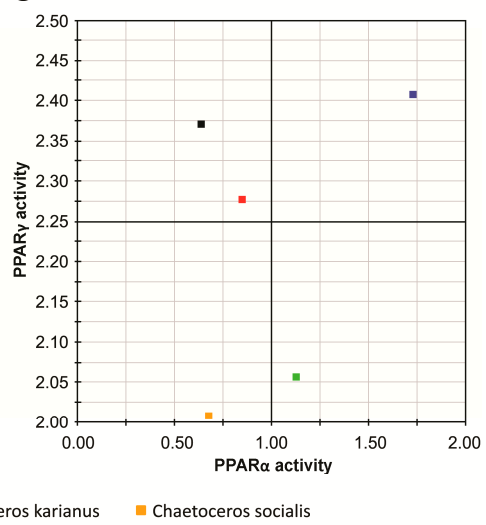

Figure 7. Principal component analysis (PCA) of solid phase extracts from Chaetoceros species shows a species-specific metabolic clustering that mirrors PPAR ligand activity from the same extracts. PCA score plots of the metabolite profile show clustering of different Chaetoceros species in positive ion (A) and negative ion (B) mode. Chromatograms were obtained with UPLC-MS ${ }^{e}$ and processed and analyzed in MarkerLynx 1.3. COS-1 cells were transfected with plasmids expressing Gal4-LBD (human PPAR $\alpha$ and $\gamma$ ) and a Gal4-responsive $L u c$ reporter. The cells were then treated with the same extracts as used for the PCA. The results representing the mean $R L U_{\text {extract }} / R_{L} U_{\text {DMSO }}$ of two independent assays performed in duplicate was plotted as PPAR $\alpha$ activity vs. PPAR $\gamma$ activity from the same organism (C).

(7E)-9-Oxohexadec-7-enoic acid (1) Colorless oil $(60 \mu \mathrm{g})$. UV $\lambda_{\max }$ (acetonitrile/ $\left.\mathrm{H}_{2} \mathrm{O}\right) 227 \mathrm{~nm}$. Negative HRESIMS $m / z$ 267.1966; $\mathrm{C}_{16} \mathrm{H}_{28} \mathrm{O}_{3}$ requires $m / z$ 267.1960. Positive high-resolution electrospray ionisation mass spectrometry (HRESIMS) $m / z$ 269.2114; $\mathrm{C}_{16} \mathrm{H}_{29} \mathrm{O}_{3}$ requires $m / z$ 269.2117.

(10E)-9-Oxohexadec-10-enoic acid (2) Colorless oil (53 $\mu \mathrm{g}$ ). UV $\lambda_{\max }$ (acetonitrile/ $\mathrm{H}_{2} \mathrm{O}$ ) $226 \mathrm{~nm}$. Negative HRESIMS $m / z$ 267.1966; $\mathrm{C}_{16} \mathrm{H}_{28} \mathrm{O}_{3}$ requires $m / z$ 267.1960. Positive HRESIMS $m / z 269.2116 ; \mathrm{C}_{16} \mathrm{H}_{29} \mathrm{O}_{3}$ requires $m / z 269.2117$.

\section{Materials and Methods}

\subsection{Biological Material}

For primary screening we used organic Flash fractions from the Marbank collection [37]. Inocula for the mass cultivation of Chaetoceros karianus were from our in-house culture collection. The microalga was isolated from north Norwegian spring bloom stocks in 2009. Mass cultivation was performed at $4.5^{\circ} \mathrm{C}$ in a temperature and irradiation-controlled room, where the microalgae were grown in $0.3 \mathrm{~m}^{3}$ transparent plexiglas cylinders with external illumination. At the start of the culture period, mean scalar irradiance across the cultivation cylinder was approximately $125 \mu \mathrm{mol} \mathrm{m}{ }^{-2} \cdot \mathrm{s}^{-1}$ and at the time of harvesting it was approximately $35 \mu \mathrm{mol} \mathrm{m}{ }^{-2} \cdot \mathrm{s}^{-1}$ due to self-shadowing. The photoperiod was 14:10 (L:D). Illumination was supplied by Osram daylight fluorescent tubes.

The culture medium was Millipore filtered $(0.1 \mu \mathrm{m}) 33.5 \mathrm{ppt}$. seawater growth media with a concentration of inorganic nutrients equivalent to $\mathrm{f} / 10$ (Sigma-Aldrich, St. Louis, MO, USA) and a surplus of silicon $(50 \mu \mathrm{mol})$. The growth rate of the cultures were monitored twice weekly by measuring the in vivo fluorescence and by microscopic inspection of the cells. The biomass 
concentrations at the start of the experiments were approximately $2 \mu \mathrm{g} \cdot \mathrm{Chl} a \cdot \mathrm{L}^{-1}$ and by time of harvested, approximately $350 \mu \mathrm{g} \cdot \mathrm{Chl} a \cdot \mathrm{L}^{-1}$. To monitor biomass development as $\mathrm{Chl} a$, a Turner fluorometer (TD-700) was applied. The cells were harvested by sieving the culture though a $10 \mu \mathrm{m}$ mesh size plankton net, thus letting any (small) amounts of bacteria to be flushed out. After collection, the cells were scraped off the plankton net and stored in $25 \mathrm{~mL}$ plastic tubes at $-80{ }^{\circ} \mathrm{C}$.

\subsection{Bioassay-Guided Isolation Platform}

\subsubsection{General Extract Preparation}

The samples were freeze-dried, ground, and stored at $-20^{\circ} \mathrm{C}$ before extraction with Milli-Q water $\left(2 \times, 24 \mathrm{~h}\right.$ and $30 \mathrm{~min}$, respectively) at $5{ }^{\circ} \mathrm{C}(20 \mathrm{mg} / \mathrm{mL})$. The extracted slurries were then centrifuged and the supernatant (the $\mathrm{H}_{2} \mathrm{O}$ extract) was removed. The pellet was then freeze-dried and ground again.

To produce the organic extract, the pellet was extracted with $\mathrm{MeOH} / \mathrm{CH}_{2} \mathrm{Cl}_{2}(1: 1)\left(2 \times\right.$ at $5{ }^{\circ} \mathrm{C}$, $24 \mathrm{~h}$ and $30 \mathrm{~min}$, respectively) making a $20 \mathrm{mg} / \mathrm{mL}$ organic extract. The extract was then filtered through Whatman filters (nr. 3, Ø $125 \mathrm{~mm}$ ) and the filtrate was evaporated in vacuo and stored at $-20^{\circ} \mathrm{C}$.

\subsubsection{Specific Extract Preparation for Bioassay-Guided Fractionation}

Organic extracts $(0.5-2 \mathrm{~g})$ from the library prepared as described above (Section 3.2.1) were reconstituted in $\mathrm{ACN} / \mathrm{H}_{2} \mathrm{O}(9: 1)$ using an ultrasound bath $(30 \mathrm{~min})$ to make a $20 \mathrm{mg} / \mathrm{mL}$ suspension. The suspension was then filtered, recovered in a separatory funnel, and defatted with hexane $(1: 1,2 \times)$. The polar organic extracts were evaporated to dryness and reconstituted in $\mathrm{ACN} / \mathrm{H}_{2} \mathrm{O}(1: 1)$, before being subjected to vacuum-aided solid phase extraction (SPE) on Strata C18-E cartridges (Phenomenex, Torrance, CA, USA). The eluates were recovered by a 5 -fold concentration $(100 \mathrm{mg} / \mathrm{mL})$.

\subsubsection{Semi-Preparative High-Performance Liquid Chromatography (Semiprep HPLC-PDA)}

The SPE-eluates were subjected to semi-preparative reverse-phase chromatography on a Luna C18 column $(250 \times 10 \mathrm{~mm}, 5 \mu \mathrm{m})$ (Phenomenex, Torrance, CA, USA). A $6 \mathrm{~mL} / \mathrm{min}$ flow of a mobile phase consisting of $0.1 \%$ formic acid (A) and $0.1 \%$ formic acid in acetonitrile (B) was employed with gradient elution starting with $5 \% \mathrm{~B}$, and rising to $100 \% \mathrm{~B}$ within $30 \mathrm{~min}$. Then isocratic elution with $100 \% \mathrm{~B}$ was performed before switching back to the initial conditions. Time-based (60 s) fractions were collected in a Waters 2767 sample manager after detection with a Waters 2998 PDA detector (Waters, Milford, MA, USA). Fractions collected were then tested in our bioassay platform, and those showing significant activity were pooled and subjected to a second round of semiprep HPLC-PDA. In this second step, we applied a gradient elution program starting with $70 \%$ A (10 mM ammonium formate and $0.1 \%$ formic acid) and 30\% B (10 mM ammonium formate and $0.1 \%$ formic acid in acetonitrile), rising to $100 \% \mathrm{~B}$ within $30 \mathrm{~min}$. Then isocratic elution with $100 \% \mathrm{~B}$ was performed before switching back to the initial conditions. Compounds $\mathbf{1}$ and $\mathbf{2}$ were collected in separate fractions by following the PDA signal trace.

\subsubsection{Plasmids}

The pSG5-Gal4-hPPAR $\alpha$-LBD, pSG5-Gal4-hPPAR $\delta$-LBD, and pSG5-Gal4-hPPAR $\gamma$-LBD encoding Gal4 DNA-binding domain (DBD; aa 1-147) fused in frame with the SV40 nuclear localization signal 1, and the ligand binding domain (LBD) of human PPAR $\alpha$ (aa 168-468), PPAR $\delta$ (aa 140-441), and PPAR $\gamma$ (aa 205-505), respectively, were received as generous gifts from Dr. Krister Bamberg (AstraZeneca, Mölndal, Sweden). The same was true for the pGL3-5 $\times$ UAS-SV40 luciferase reporter consisting of five Upstream Activation Sequences (UAS; 25 bp phasing) and a SV40 early promoter in front of the Firefly Luciferase gene. The plasmid encoding full-length human PPAR $\gamma, \mathrm{pcDNA3.1-hPPARg2-FLAG,}$ was made by PCR amplification of human PPARG CDNA, using custom-made primers (harboring 
kozak and FLAG-tag), and subcloning it into pcDNA3.1(+) (Life Technologies, Carlsbad, CA, USA) between NheI and NotI. The corresponding PPAR $\alpha$ plasmid, pcDNA3.1-hPPARa-FLAG, was made by PCR amplification of human PPARA $c D N A$ and subcloning it into pcDNA3.1-hPPARg2-FLAG between NheI and BamHI, exchanging PPARG with PPARA, and keeping the FLAG tag. The plasmid encoding full-length human $\mathrm{RXR} \alpha$, pcDNA3-hRXR $\alpha$, has been described earlier [38]. The human PLIN1-driven reporters, pGL3-hPLIN1-3' del and pGL3-hPLIN1-3'del-PPREmut, have been described before [7]. The human CPT1A-driven reporters, pGL3-hCPT1AInt and pGL3-hCPT1AInt-PPREmut, were received as a gift from Prof. Diego Haro Bautista and have been described previously [39]. The vector pRL-CMV (Promega, Madison, WI, USA), constitutively expressing Renilla Luciferase, was used as a control of transfection efficiency. All cloned plasmids have been sequenced. Cloning primer sequences are available upon request.

\subsubsection{Cell Culture, Transfection, and Luciferase Assays}

COS-1 cells (ATCC ${ }^{\circledR}$ CRL-1650) were maintained in DMEM (Life Technologies, Carlsbad, CA, USA) containing gentamicin $(10 \mu \mathrm{g} / \mathrm{mL})$ or penicillin/streptomycin $(50 \mathrm{U} / \mathrm{mL} ; 50 \mu \mathrm{g} / \mathrm{mL})$ and $10 \%$ fetal bovine serum (F7524; Sigma), at $37{ }^{\circ} \mathrm{C}$ in a humidified atmosphere of $5 \% \mathrm{CO}_{2}$ in air. Cell confluence never exceeded $80 \%$ before subculturing or transfection. For the screening campaign the COS-1 cells were transiently transfected with $1.7 \mu \mathrm{g}$ of the Gal4-PPAR-LBD expression plasmids and $8.5 \mu \mathrm{g}$ of the $5 \times \mathrm{UAS}-\mathrm{SV} 40$ luciferase reporter per $1 \times 10^{7}$ cells, using the Neon Transfection System (Life Technologies, Carlsbad, CA, USA). The cells were then plated at $2 \times 10^{4}$ cells $/$ well in white 96-well plates (F96, Nalge Nunc Int., Rochester, NY, USA) and allowed to attach ( $5 \mathrm{~h}$ ) before the different fractions were added at two concentrations (final DMSO concentration of $0.35 \%$ or $0.70 \%$ ). Corresponding volumes of DMSO was used as the negative control. As positive controls, the following synthetic agonist were used; PPAR $\alpha$ : Bezafibrate (BM-15075; B7273, Sigma-Aldrich, St. Louis, MO, USA) or Pirinixic acid (WY-14643; C7081, Sigma-Aldrich, St. Louis, MO, USA), PPARס: GSK-516 (GW-501516; 43732, Sigma-Aldrich, St. Louis, MO, USA), and PPAR $\gamma$ : Rosiglitazone (BRL-49653; Cayman Chemical, Ann Arbor, MI, USA). After $18 \mathrm{~h}$ the cells were washed with PBS, before D-luciferin potassium salt dissolved in $30 \mathrm{mM}$ HEPES $(0.12 \mathrm{mg} / \mathrm{mL})$, supplemented with $1 \mathrm{mM} \mathrm{MgSO}_{4}$ and $0.5 \mathrm{mM}$ adenosine triphosphate was added directly to the wells $(50 \mu \mathrm{L} /$ well). Following $10 \mathrm{~min}$ of incubation at room temperature, the emitted light signal was measured on an Envision reader (PerkinElmer, Turku, Finland).

For the verification of hits, dose-response assays, and specificity assays, COS- 1 cells were seeded at $7 \times 10^{4}$ cells/well in 24-well plates. After $24 \mathrm{~h}$, the cells were transfected with $0.1 \mu \mathrm{g}$ of the Gal4-DBD-PPAR-LBD expression plasmids, $0.2 \mu \mathrm{g}$ of the $5 \times \mathrm{UAS}-\mathrm{SV} 40$ luciferase reporter, and $0.05 \mu \mathrm{g}$ of the Renilla Luciferase-coding internal control using Lipofectamin 2000 (Life Technologies, Carlsbad, CA, USA). After $5 \mathrm{~h}$, the fractions or semi-pure compounds in DMSO (final conc. $0.7 \%$ ) were added to the culture and the incubation continued overnight. After $18 \mathrm{~h}$, the cells were washed in PBS and lysed in Passive Lysis Buffer (Promega, Madison, WI, USA) and the Dual-Luciferase ${ }^{\circledR}$ ReporterAssay System (Promega, Madison, WI, USA) was run on a Synergy 2 plate reader (BioTek, Winooski, VT, USA) following the manufacturer's protocol. The Firefly Luciferase readings were normalized to the Renilla Luciferase numbers and data from at least two independent transfection experiments, run in duplicate, are presented.

\subsection{Structure Elucidation Platform}

3.3.1. Ultra-Performance Liquid Chromatography Coupled to Data-Independent Mass Spectrometry (UPLC-MSe)

High resolution mass spectra (UPLC-QToFMS) were recorded in positive and negative mode, making use of both electrospray (ESI) and atmospheric pressure chemical ionization (APCI) interfaces on a Xevo G2 QToF mass spectrometer (Waters, Milford, MA, USA). The following settings were 
applied in both ESI negative and ESI positive MS: Capillary voltage $0.5 \mathrm{kV}$, source and desolvation temperatures of $130{ }^{\circ} \mathrm{C}$ and $400{ }^{\circ} \mathrm{C}$, respectively, cone and desolvation gas at $20 \mathrm{~L} / \mathrm{h}$ and $800 \mathrm{~L} / \mathrm{h}$, respectively. The instrument was run in MS e resolution mode with a scan time of $0.1 \mathrm{~s}$, centroid mode. Low energy (no collision energy) and high energy (ramp collision energy from 30 to $50 \mathrm{~V}$ ) spectra were acquired in the mass range from $m / z 100-1200$. The instrument was regularly calibrated with sodium formate with leucine enkephaline applied as a lock mass.

Chromatographic analysis was performed using an Aquity $50 \times 2.1 \mathrm{~mm}$ (i.d.) $1.7 \mu \mathrm{m}$ UPLC BEH C18 column (Waters, Milford, MA, USA) with a mobile phase consisting of $0.1 \%$ formic acid (A) and $0.1 \%$ formic acid in acetonitrile (B). Different linear gradient programs were applied for scouting and compound-directed chromatography. The longer scouting program applied in the initial studies on complex mixtures was as follows: $90 \%$ A was kept for the first 2 min, then elution from 10 to $100 \%$ B over $25 \mathrm{~min}$ with a $10 \mathrm{~min}$ hold at $100 \%$ B before the eluent was switched back to the initial conditions. The shorter program was as follows: $98 \%$ A kept constant for $2 \mathrm{~min}$, then elution from 2 to $100 \%$ B over $3 \mathrm{~min}$ and hold at $100 \% \mathrm{~B}$ for $2 \mathrm{~min}$ before switching back to the initial conditions. A mobile phase flow rate of $0.6 \mathrm{~mL} / \mathrm{min}$ was used, and $2-10 \mu \mathrm{L}$ samples were injected.

\subsubsection{Ultra-Performance Liquid Chromatography Coupled to Photodiode Array Detection (UPLC-PDA)}

The chromatographic features applied in the UPLC-PDA analysis were similar to those described above (Section 3.3.1), including column type, mobile phase, and elution properties. The UV spectra were recorded with an Acquity PDA detector (Waters, Milford, MA, USA) between 210 and $600 \mathrm{~nm}$. The wavelength resolution was $1.2 \mathrm{~nm}$.

\subsubsection{NMR Spectroscopy}

NMR spectra of compounds 1 and 2 were obtained from solutions $(500 \mu \mathrm{L})$ in acetonitrile- $d_{3}$ $\left(\mathrm{CD}_{3} \mathrm{CN}\right.$, 99.96 atom \% D; Sigma-Aldrich, St. Louis, MO, USA) using $5 \mathrm{~mm}$ o.d. Wilmad tubes (Sigma-Aldrich, St. Louis, MO, USA). The spectra were acquired on an Avance AVII $600 \mathrm{MHz}$ NMR spectrometer (Bruker BioSpin GmbH, Rheinstetten, Germany) equipped with a $5 \mathrm{~mm}$ CP-TCI triple resonance inverse cryoprobe with a Z-gradient coil. NMR assignments were obtained from the examination of ${ }^{1} \mathrm{H}$, DEPT135, 1-D SELTOCSY, COSY, TOCSY, g-HSQC, g-HMBC, HSQC-TOCSY, and NOESY NMR spectra. The data were processed using Bruker TOPSPIN (version 2.1 pl4 or version 3) software. Chemical shifts, determined at $25{ }^{\circ} \mathrm{C}$, were reported relative to internal $\mathrm{CHD} 2 \mathrm{CN}$ (1.96 ppm) and $\mathrm{CD} 3 \mathrm{CN}$ (118.26 ppm).

\subsection{Metabolomics}

Diluted SPE-eluates $(1 \mu \mathrm{g} / \mathrm{mL})$ of the species C. decipiens, C. diadema, C. furcellatus, C. karianus, and C. socialis were analyzed following the protocol described above (Section 3.3.1) in UPLC-MS ${ }^{\mathrm{e}}$ in both ESI positive and negative mode. The chromatograms obtained from the UPLC-MS analyses were processed by the MarkerLynx 1.3 application manager (Waters, Milford, MA, USA) for mass signal extraction and alignment. MarkerLynx makes use of ApexTrack for peak detection and integration, listing the detected peaks as their $\mathrm{m} / \mathrm{z}$ values and retention times along with their associated intensities. When the data are collected, they are automatically delivered to the Extended Statistics software integrated in MarkerLynx and multivariate statistics are applied for unsupervised principal components analyses (PCA). The parameters applied in the MarkerLynx application manager were as follows: XIC windows, $0.02 \mathrm{Da}$; marker intensity, 1200; mass windows, $0.02 \mathrm{Da}$; retention window, 0.1; the Apex Track peak parameters were automatically calculated by MarkerLynx. The isotopes were not included in the peak detection process. 


\section{Conclusions}

We have identified two isomeric oxo-fatty acids from Chaetoceros karianus with apparent dual PPAR $\alpha / \gamma$ agonist activity. These oxo-fatty acids also show a limited isoform-specificity. (7E)-9-oxohexadec-7-enoic acid mainly activates PPAR $\gamma$, while (10E)-9-oxohexadec-10-enoic acid primarily activates PPAR $\alpha$. Principal component analyses indicate that $C$. karianus differs from other Chaetoceros species, both with respect to the metabolic profile and the PPAR activity. This finding holds the potential of defining a PPAR pharmacophore with tunable activity and specificity.

Supplementary Materials: The following are available online at www.mdpi.com/1660-3397/15/6/148/s1, Table S1: PPAR agonist activity found in the Marbank collection.

Acknowledgments: We thank Marbank for providing the samples used for the primary screening campaign. This research was supported by the Research Council of Norway, grant nr. 174885/130 and 08452/O10. The authors thank Pronova Biopharma, now a part of BASF, for financial support, and Krister Bamberg and Diego Haro Bautista for providing us with plasmids.

Author Contributions: Hilde I. Nebb, Terje Larsen and Steinar M. Paulsen conceived the study, Angel Moldes-Anaya, Thomas Sæther and Steinar M. Paulsen conceived and designed the experiments; Angel Moldes-Anaya, Thomas Sæther and Steinar M. Paulsen performed the experiments; Angel Moldes-Anaya, Thomas Sæther, Steinar M. Paulsen, and Silvio Uhlig analyzed the data; Hilde I. Nebb, Hans C. Eilertsen, and Terje Larsen critically read the manuscript and participated in the writing process; Hans C. Eilertsen contributed with microalgae cultures from the Algtech Planktonlab, UiT collection; Angel Moldes-Anaya, Thomas Sæther, and Steinar M. Paulsen wrote the paper.

Conflicts of Interest: The authors declare no conflict of interest. The founding sponsors had no role in the design of the study; in the collection, analyses, or interpretation of data; in the writing of the manuscript, and in the decision to publish the results.

\section{References}

1. Ferre, P. The biology of peroxisome proliferator-activated receptors: Relationship with lipid metabolism and insulin sensitivity. Diabetes 2004, 53 (Suppl. 1), S43-S50. [CrossRef] [PubMed]

2. Kliewer, S.A.; Sundseth, S.S.; Jones, S.A.; Brown, P.J.; Wisely, G.B.; Koble, C.S.; Devchand, P.; Wahli, W.; Willson, T.M.; Lenhard, J.M.; et al. Fatty acids and eicosanoids regulate gene expression through direct interactions with peroxisome proliferator-activated receptors $\alpha$ and $\gamma$. Proc. Natl. Acad. Sci. USA 1997, 94, 4318-4323. [CrossRef] [PubMed]

3. Itoh, T.; Fairall, L.; Amin, K.; Inaba, Y.; Szanto, A.; Balint, B.L.; Nagy, L.; Yamamoto, K.; Schwabe, J.W. Structural basis for the activation of PPAR $\gamma$ by oxidized fatty acids. Nat. Struct. Mol. Biol. 2008, 15, 924-931. [CrossRef] [PubMed]

4. Nolte, R.T.; Wisely, G.B.; Westin, S.; Cobb, J.E.; Lambert, M.H.; Kurokawa, R.; Rosenfeld, M.G.; Willson, T.M.; Glass, C.K.; Milburn, M.V. Ligand binding and co-activator assembly of the peroxisome proliferator-activated receptor- $\gamma$. Nature 1998, 395, 137-143. [PubMed]

5. Auboeuf, D.; Rieusset, J.; Fajas, L.; Vallier, P.; Frering, V.; Riou, J.P.; Staels, B.; Auwerx, J.; Laville, M.; Vidal, H. Tissue Distribution and Quantification of the Expression of mRNAs of Peroxisome Proliferator-Activated Receptors and Liver X Receptor- $\alpha$ in Humans: No Alteration in Adipose Tissue of Obese and NIDDM Patients. Diabetes 1997, 46, 1319-1327. [CrossRef] [PubMed]

6. Chawla, A.; Schwarz, E.J.; Dimaculangan, D.D.; Lazar, M.A. Peroxisome proliferator-activated receptor (PPAR) gamma: Adipose-predominant expression and induction early in adipocyte differentiation. Endocrinology 1994, 135, 798-800. [CrossRef] [PubMed]

7. Dalen, K.T.; Schoonjans, K.; Ulven, S.M.; Weedon-Fekjaer, M.S.; Bentzen, T.G.; Koutnikova, H.; Auwerx, J.; Nebbl, H.I. Adipose tissue expression of the lipid droplet-associating proteins S3-12 and perilipin is controlled by peroxisome proliferator-activated receptor- $\gamma$. Diabetes 2004, 53, 1243-1252. [CrossRef] [PubMed]

8. Tontonoz, P.; Hu, E.; Spiegelman, B.M. Stimulation of adipogenesis in fibroblasts by PPAR $\gamma 2$, a lipid-activated transcription factor. Cell 1994, 79, 1147-1156. [CrossRef]

9. He, W.; Barak, Y.; Hevener, A.; Olson, P.; Liao, D.; Le, J.; Nelson, M.; Ong, E.; Olefsky, J.M.; Evans, R.M. Adipose-specific peroxisome proliferator-activated receptor $\gamma$ knockout causes insulin resistance in fat and liver but not in muscle. Proc. Natl. Acad. Sci. USA 2003, 100, 15712-15717. [CrossRef] [PubMed] 
10. Barrero, M.J.; Camarero, N.; Marrero, P.F.; Haro, D. Control of human carnitine palmitoyltransferase II gene transcription by peroxisome proliferator-activated receptor through a partially conserved peroxisome proliferator-responsive element. Biochem. J. 2003, 369, 721-729. [CrossRef] [PubMed]

11. Mandard, S.; Muller, M.; Kersten, S. Peroxisome proliferator-activated receptor alpha target genes. Cell. Mol. Life Sci. 2004, 61, 393-416. [CrossRef] [PubMed]

12. Wang, H.; Sztalryd, C. Oxidative tissue: Perilipin 5 links storage with the furnace. Trends Endocrinol. Metab. 2011, 22, 197-203. [CrossRef] [PubMed]

13. Hotamisligil, G.S.; Shargill, N.S.; Spiegelman, B.M. Adipose expression of tumor necrosis factor- $\alpha$ : Direct role in obesity-linked insulin resistance. Science 1993, 259, 87-91. [CrossRef] [PubMed]

14. Lagathu, C.; Yvan-Charvet, L.; Bastard, J.P.; Maachi, M.; Quignard-Boulange, A.; Capeau, J.; Caron, M. Long-term treatment with interleukin- $\beta$ induces insulin resistance in murine and human adipocytes. Diabetologia 2006, 49, 2162-2173. [CrossRef] [PubMed]

15. Steppan, C.M.; Bailey, S.T.; Bhat, S.; Brown, E.J.; Banerjee, R.R.; Wright, C.M.; Patel, H.R.; Ahima, R.S.; Lazar, M.A. The hormone resistin links obesity to diabetes. Nature 2001, 409, 307-312. [CrossRef] [PubMed]

16. Bluher, M. Adipose tissue inflammation: A cause or consequence of obesity-related insulin resistance? Clin. Sci. 2016, 130, 1603-1614. [CrossRef] [PubMed]

17. Moran-Salvador, E.; Lopez-Parra, M.; Garcia-Alonso, V.; Titos, E.; Martinez-Clemente, M.; Gonzalez-Periz, A.; Lopez-Vicario, C.; Barak, Y.; Arroyo, V.; Claria, J. Role for ppargamma in obesity-induced hepatic steatosis as determined by hepatocyte- and macrophage-specific conditional knockouts. FASEB J. 2011, 25, 2538-2550. [CrossRef] [PubMed]

18. Jones, D. Potential remains for PPAR-targeted drugs. Nat. Rev. Drug Discov. 2010, 9, 668-669. [CrossRef] [PubMed]

19. Lehmann, J.M.; Moore, L.B.; Smith-Oliver, T.A.; Wilkison, W.O.; Willson, T.M.; Kliewer, S.A. An antidiabetic thiazolidinedione is a high affinity ligand for peroxisome proliferator-activated receptor $\gamma$ (PPAR $\gamma)$. J. Biol. Chem. 1995, 270, 12953-12956. [CrossRef] [PubMed]

20. Schoonjans, K.; Watanabe, M.; Suzuki, H.; Mahfoudi, A.; Krey, G.; Wahli, W.; Grimaldi, P.; Staels, B.; Yamamoto, T.; Auwerx, J. Induction of the Acyl-Coenzyme A Synthetase Gene by Fibrates and Fatty Acids is Mediated by a Peroxisome Proliferator Response Element in the C Promoter. J. Biol. Chem. 1995, 270, 19269-19276. [PubMed]

21. Nissen, S.E.; Wolski, K. Effect of rosiglitazone on the risk of myocardial infarction and death from cardiovascular causes. N. Engl. J. Med. 2007, 356, 2457-2471. [CrossRef] [PubMed]

22. Jonas, D.; Van Scoyoc, E.; Gerrald, K.; Wines, R.; Amick, H.; Triplette, M.; Runge, T. Drug Class Review: Newer Diabetes Medications, TZDs, and Combinations: Final Original Report; Oregon Health \& Science University: Portland, OR, USA, 2011.

23. Amato, A.A.; Rajagopalan, S.; Lin, J.Z.; Carvalho, B.M.; Figueira, A.C.; Lu, J.; Ayers, S.D.; Mottin, M.; Silveira, R.L.; Souza, P.C.; et al. GQ-16, a novel peroxisome proliferator-activated receptor $\gamma$ (PPAR $\gamma$ ) ligand, promotes insulin sensitization without weight gain. J. Biol. Chem. 2012, 287, 28169-28179. [CrossRef] [PubMed]

24. Choi, J.H.; Banks, A.S.; Kamenecka, T.M.; Busby, S.A.; Chalmers, M.J.; Kumar, N.; Kuruvilla, D.S.; Shin, Y.; He, Y.; Bruning, J.B.; et al. Antidiabetic actions of a non-agonist PPAR $\gamma$ ligand blocking CDK5-mediated phosphorylation. Nature 2011, 477, 477-481. [CrossRef] [PubMed]

25. Tan, C.K.; Zhuang, Y.; Wahli, W. Synthetic and natural peroxisome proliferator-activated receptor (PPAR) agonists as candidates for the therapy of the metabolic syndrome. Expert Opin. Ther. Targets 2017, 21, 333-348. [CrossRef] [PubMed]

26. Fievet, C.; Fruchart, J.C.; Staels, B. PPAR $\alpha$ and PPAR $\gamma$ dual agonists for the treatment of type 2 diabetes and the metabolic syndrome. Curr. Opin. Pharmacol. 2006, 6, 606-614. [CrossRef] [PubMed]

27. Hasle, G.R.; Syvertsen, E.E. Marine diatoms. In Identifying Marine Phytoplankton; Academic Press Ltd.: Cambridge, MA, USA, 1997; pp. 5-385.

28. Toyoda, K.; Nagasaki, K.; Williams, D.M.; Tomaru, Y. PCR-RFLP analysis for species-level distinction of the genus chaetoceros Ehrenberg (Bacillariophyceae). Hiyoshi Rev. Nat. Sci. 2011, 50, 21-29.

29. Huseby, S.; Degerlund, M.; Eriksen, G.K.; Ingebrigtsen, R.A.; Eilertsen, H.C.; Hansen, E. Chemical diversity as a function of temperature in six northern diatom species. Mar. Drugs 2013, 11, 4232-4245. [CrossRef] [PubMed] 
30. Ingebrigtsen, R.; Hansen, E.; Andersen, J.; Eilertsen, H. Light and temperature effects on bioactivity in diatoms. J. Appl. Phycol. 2015, 28, 939-950. [CrossRef] [PubMed]

31. D'Ippolito, G.; Cutignano, A.; Briante, R.; Febbraio, F.; Cimino, G.; Fontana, A. New C16 fatty-acid-based oxylipin pathway in the marine diatom Thalassiosira rotula. Org. Biomol. Chem. 2005, 3, 4065-4070. [CrossRef] [PubMed]

32. Dang, H.T.; Lee, H.J.; Yoo, E.S.; Shinde, P.B.; Lee, Y.M.; Hong, J.; Kim, D.K.; Jung, J.H. Anti-inflammatory constituents of the red alga gracilaria verrucosa and their synthetic analogues. J. Nat. Prod. 2008, 71, 232-240. [CrossRef] [PubMed]

33. Gottlieb, H.E.; Kotlyar, V.; Nudelman, A. NMR chemical shifts of common laboratory solvents as trace impurities. J. Org. Chem. 1997, 62, 7512-7515. [CrossRef] [PubMed]

34. Kenner, G.W.; Stenhagen, E. Location of double bonds by mass spectrometry. Acta Chem. Scand. 1964, 18, 1551-1552. [CrossRef]

35. Jain, M.R.; Giri, S.R.; Trivedi, C.; Bhoi, B.; Rath, A.; Vanage, G.; Vyas, P.; Ranvir, R.; Patel, P.R. Saroglitazar, a novel PPAR $\alpha / \gamma$ agonist with predominant PPAR $\alpha$ activity, shows lipid-lowering and insulin-sensitizing effects in preclinical models. Pharmacol. Res. Perspect. 2015, 3, e00136. [CrossRef] [PubMed]

36. Yore, M.M.; Syed, I.; Moraes-Vieira, P.M.; Zhang, T.; Herman, M.A.; Homan, E.A.; Patel, R.T.; Lee, J.; Chen, S.; Peroni, O.D.; et al. Discovery of a class of endogenous mammalian lipids with anti-diabetic and anti-inflammatory effects. Cell 2014, 159, 318-332. [CrossRef] [PubMed]

37. Svenson, J. Mabcent: Arctic marine bioprospecting in Norway. Phytochem. Rev. 2013, 12, 567-578. [CrossRef] [PubMed]

38. Weedon-Fekjaer, M.S.; Dalen, K.T.; Solaas, K.; Staff, A.C.; Duttaroy, A.K.; Nebb, H.I. Activation of LXR increases acyl-CoA synthetase activity through direct regulation of ACSL3 in human placental trophoblast cells. J. Lipid Res. 2010, 51, 1886-1896. [CrossRef] [PubMed]

39. Napal, L.; Marrero, P.F.; Haro, D. An intronic peroxisome proliferator-activated receptor-binding sequence mediates fatty acid induction of the human carnitine palmitoyltransferase 1A. J. Mol. Biol. 2005, 354, 751-759. [CrossRef] [PubMed] 